\title{
Büyüme hormonları ve aktif kömürün in vitro koşullarda kardelen (Galanthus woronowii Losinsk.) soğancık oluşumuna etkisi
}

\section{Effects of plant growth regulators and activated charcoal on in vitro formation of bulblet in snowdrop (Galanthus woronowii)}

\section{Elif YÜZBAŞIOĞLU, Eda DALYAN}

İstanbul Üniversitesi, Fen Fakültesi, Biyoloji Bölümü, Botanik Anabilim Dalı, Süleymaniye, İstanbul, Türkiye

Sorumlu yazar (Corresponding author): E. Yüzbaşıŏlu, e-posta (e-mail): aytamka@istanbul.edu.tr

\section{MAKALE BİLGİSİ}

Alınış tarihi 03 Mayıs 2017

Düzeltilme tarihi 07 Temmuz 2017

Kabul tarihi 10 Ekim 2017

\section{Anahtar Kelimeler:}

Aktif kömür

In vitro

Kardelen

\begin{abstract}
$\ddot{O Z Z}$
Ülkemiz topraklarında yetişen kardelen, tür çeşitliliği ve endemik zenginliği bakımından önemli bir değere sahiptir. Biyoteknolojik yöntemler kullanılarak, kardelen soğanının sürdürülebilir üretimine ihtiyaç duyulmaktadır. Bu çalışmada, Karadeniz kardelen soğanının in vitro koşullarda üretilmesi için, farklı bitki büyüme düzenleyicileri ve aktif kömür kullanılarak en verimli ve uygun ortamın bulunması hedeflenmiștir. Bu amac ile, BAP, NAA, GA ve $_{2,4}$ D bitkisel hormon kombinasyonları ve farklı konsantrasyonlarda aktif kömür içeren MS besiyeri ortamlarında soğancık oluşumu teșvik edilmiștir. Uygulanan hormon kombinasyonları arasında $1 \mathrm{mg} \mathrm{l}^{-1}$ BAP ve $0.1 \mathrm{mg} \mathrm{l}^{-1}$ NAA içeren MS ortamında 3.67 adet soğancık elde edilmiştir. En yüksek soğancık sayısı ise, $5 \mathrm{~g} \mathrm{l}^{-1}$ aktif kömür içeren MS besiyerinde eksplant başına ortalama 5.95 adet bulunmuştur. Doku kültürü koşullarında elde edilen tüm soğancıklar, $1 \mathrm{~g} \mathrm{l}^{-1}$ ve $5 \mathrm{~g} \mathrm{l}^{-1}$ aktif kömür içeren MS besiyeri ortamında köklendirilmiş ve dış ortama aktarımları gerçekleștirilmiștir. Sonuç olarak, in vitro koșullarda kullanılan tüm ortamlar arasında, aktif kömür uygulamasının en yüksek soğancık oluşumunu teşvik ettiğ ortaya konmuştur.
\end{abstract}

\section{ARTICLE INFO}

\section{Received 03 May 2017}

Received in revised form 07 July 2017

Accepted 10 October 2017

\section{Keywords:}

Activated charcoal

In vitro

Snowdrop

\begin{abstract}
The snow drop has a wide distribution of our country is an important plant in terms of species diversity and endemic richness. Due to widespread use as ornamental plant, it has commercial economic value. For this reason, sustainable production of snowdrop bulbs is needed using biotechnological methods. In this study, it was aimed to find the optimum and efficient conditions of snowdrop bulb in vitro using different plant growth regulators and activated charcoal. For this purpose, BAP, NAA, $\mathrm{GA}_{3}$ and 2,4-D plant growth regulators combinations and active charcoal at different concentrations were used in MS medium. While bulblet number were found 3.67 in MS medium containing $1 \mathrm{mg} \mathrm{l}^{-1} \mathrm{BAP}$ and $0.1 \mathrm{mg} \mathrm{l}^{-1} \mathrm{NAA}$ among applied hormone combination, the highest bulblet number per explant as 5.95 were observed on MS medium containing and $5 \mathrm{~g} \mathrm{l}^{-1}$ activated charcoal. In vitro rooting of bulblets used MS medium supplemented with $1 \mathrm{~g} \mathrm{l}^{-1}$ and $5 \mathrm{~g} \mathrm{l}^{-1}$ activated charcoal and then acclimatization of bulblet were done successfully. Consequently, the result from the experiment, activated charcoal promoted the highest bulblet multiplication in vitro. Among the hormone combinations applied, 3.67 shallots were obtained in MS medium containing $1 \mathrm{mg} \mathrm{l}^{-1} \mathrm{BAP}$ and $0.1 \mathrm{mg} \mathrm{l}^{-1} \mathrm{NAA}$.
\end{abstract}

\section{Giriş}

Doğadan toplanan ve süs bitkisi olarak ihraç edilen soğanlı bitkilerin ticaretinde ilk sirada kardelen (Galanthus) cinsi yer almaktadır. Ülkemizde bu cinsin çok sayıda taksonu bulunmakla birlikte, sadece Toros dağlarında yetişen Galanthus elwesii Hook. f. (Toros Kardeleni) ve Doğu Karadeniz dağlarında yetişen G. woronowii Losinsk. (Karadeniz
Kardeleni) türlerinin soğanlarının ihracatı yapılmaktadır (Ekim ve ark. 1992; Yüzbaşığlu 2012).

Kardelen ihracatı ile ilgili yapılan çalışmalarda, soğanların zamansız, düzensiz, gelişigüzel ve aşırı toplanmasının, bu türlerin popülasyonlarına büyük zarar verdiği gösterilmiştir (Yüzbaşıŏglu 2008; Demir 2010). Bu nedenle ilk olarak 1989 
yılında yayımlanan bir yönetmelik ile bu bitkinin doğadan toplanması ve ihracatının yapılması ile ilgili, usul ve koşullar, kontrol altına alınmaya çalışılmıştır (Ekim ve ark. 1992; Anonim 2004; Demir 2010).

Kardelen doğal ortamında tohum ve yeni soğancık oluşumuyla çoğalmaktadır. Tohumdan, yeni olgun bir soğan oluşumu için 3-4 sene gibi uzun bir süre geçmesi gerekmektedir. Hem doğal ortamından soğanların sökülmesi hem de bitkinin doğal hayat döngüsünün uzun olması nedeniyle, kardelen cinsine ait türler giderek azalmakta ve bitkinin üretimine yönelik hızlı çoğaltım yöntemlerinin kullanılması zorunlu hale gelmektedir. Son yıllarda soğanlı bitkiler ile ilgili yapılan in vitro çalışmalarda hızlı bir artış gözlenmektedir (Ulus ve Seyidoğlu 2006; Daneshvar-Royandazagh ve ark. 2014; Çı̆̆ ve Başdoğan 2015; Özdemir ve ark. 2016). Ülkemizde ilk olarak, Çakırlar ve ark. (1994), Galanthus elwesii ve Galanthus ikariae Baker türlerinin soğan, yaprak ve çiçek sapını eksplant kaynağı olarak kullanarak, doku kültürü yöntemi ile soğancık üretimini gerçekleştirmişlerdir. Bu çalışmada, soğan pul yapraklarının en uygun eksplant kaynağı olduğu tespit edilmiştir. Diğer bir çalışmada ise, eksplant kaynağı olarak, $G$. elwesii tohumlarından elde edilen olgunlaşmamıș embriyolar kullanılmıştır (Nasırcılar ve Karagüzel 2006). Kardelen soğancık oluşumu çalışmalarında genellikle, benzil amino purin (BAP) ve naftalen asetik asit (NAA) bitkisel hormon kombinasyonları kullanılmışıtır (Tıpırdamaz ve ark. 1999; Staikidou ve ark. 2006; Nasircilar ve Karagüzel 2006). G. nivalis, G. nivalis 'Flore Pleno' ve G. elwesii türleri ile yapılan diğer bir doku kültürü çalışmasında ise, soğan pul yapraklarından $1 \mathrm{mg} \mathrm{l}^{-1} \mathrm{BA}$ ve $0.1 \mathrm{mg} \mathrm{l}^{-1}$ NAA hormon konsantrasyonları içeren MS ortamında soğancık elde edilmiş; aktif kömür içeren MS ortamında, soğancık büyümesinde, kök sayısında ve uzamasında önemli bir artış görülmüştür (Staikidou ve ark. 2006; Staikidou ve Selby 2012). Tipırdamaz (2003) yaptığı çalışmada, Galanthus ikariae soğan pul yapraklarından in vitro koşullarda elde edilen soğancıkların NAA içeren MS ortamında etkili oranda köklenme gösterdiğini bulmuştur (Tipirdamaz 2003).

Yapılan tüm bu çalışmalarda, genellikle BA ve NAA bitkisel hormonlarının az sayıda kombinasyonu kullanılmıştır. Aktif kömür uygulaması ise, sadece soğancık büyümesi üzerine çalışılmıştır. Bu çalışmada ise, Karadeniz kardeleni (Galanthus woronowii) soğan pullarından, bitkisel hormonların (BAP, NAA, $\mathrm{GA}_{3}$ ve 2,4-D) farkl1 konsantrasyonlar1 ve kombinasyonlarının in vitro koşullarda soğancık oluşumu üzerine etkisi araştırılmıştır. Ayrıca, MS ortamında aktif kömürün farklı konsantrasyonlarının teşvik ettiği soğancık oluşumunu çalışılmıştır. Çalışmanın sonucunda, in vitro kardelen soğancık üretiminde en verimli ve uygun ortamın bulunması hedeflenmiştir.

\section{Materyal ve Yöntem}

Çalışmamızda kullanılan bitkisel materyal olan Karadeniz kardeleni (Galanthus woronowii) Trabzon ili Sürmene ilçesinden Bilgin Ticaret (Süleyman Bilgin) tarafindan temin edilmiştir. Yaklaşık 150 adet olgun kardelen soğanı kullanılmıştır. Bitki doku kültürü ortamı olarak $30 \mathrm{~g} \mathrm{l}^{-1}$ sukroz ve $2.5 \mathrm{~g}$ pyhtagel içeren MS (Murashige ve Skoog 1962; Duchefa M0221) kullanılmıştır. MS ortamının ph değeri 5.7 olarak ayarlanmıştır. Hazırlanan besi ortamları $121^{\circ} \mathrm{C}$ de $20 \mathrm{dk}$ steril edilmiştir. Sterilizasyon sonrası, vitamin karışımı $1 \mathrm{mg} \mathrm{l}^{-1}$ oranında (sigma, M3900) eklenmiştir. Besiyeri ortamı soğuduktan sonra aşağıda belirtilen hormon kombinasyonları eklenerek steril petrilere ve filtreli kültür kaplarına (Duchefa, E1654-80 mm, E1674-140 mm) dökülmüştür. Bitkisel hormon kombinasyonlar1 $2 \mathrm{mg} \mathrm{l}^{-1} \mathrm{BAP}$ (benzil amino pürin) ve 0.2 $\mathrm{mg} \mathrm{l}^{-1}$ NAA (naftalen asetik asit), $1 \mathrm{mg} \mathrm{l}^{-1}$ BAP ve $0.1 \mathrm{mg} \mathrm{l}^{-1}$ NAA, $1 \mathrm{mg} \mathrm{l}^{-1}$ BAP, $0.1 \mathrm{mg} \mathrm{l}^{-1}$ NAA ve $0.1 \mathrm{mg} \mathrm{l}^{-1} \mathrm{GA}_{3}$ (giberellik asit), $2.0 \mathrm{mg} \mathrm{l}^{-1} \mathrm{GA}_{3}, 0.1 \mathrm{mg} \mathrm{l}^{-1} \mathrm{NAA}$ ve $1 \mathrm{mg} \mathrm{l}^{-1} 2,4-$ $\mathrm{D}, \quad 0.2 \mathrm{mg} \mathrm{l}^{-1} \mathrm{NAA}$ ve $2 \mathrm{mg} \mathrm{l}^{-1}$ 2,4-D olacak şekilde kullanılmıştır. MS ortamındaki aktif kömür ise, sterilizasyon aşamasından önce 1 ve $5 \mathrm{~g} \mathrm{l}^{-1}$ oranında ilave edilmiştir.

Sterilizasyon işleminde dış kabukları soyulan soğanlar, 30 dk akan musluk suyu altında yıkanmıştır. Daha sonra, $30 \mathrm{dk}$ $\% 50$ çamaşır suyunda bekletilerek, steril koşullarda 4 parçaya bölünmüştür. Parçalanan soğanlar tekrar $30 \mathrm{dk} \% 10$ çamaşır suyunda bekletildikten sonra, 3 defa steril su ile 10 ar dakika yıkanmıştır. Sterilizasyon işlemi tamamlanan soğan pulları steril filtre kağıdı ile kurulanarak, $1 \mathrm{~cm}$ büyüklügünde eksplantlar elde edilmiştir. Doku kültürü çalışması, bitki büyüme kabini koşullarında (VB 0714, Bioline, Vötsch Industrietechnik, Almanya; iç boyutlar: 970x750x1400; 1ş1k yoğunluğu:450 mmol m $\left.{ }^{-2} \mathrm{~s}^{-1} @ 200 \mathrm{~mm}\right) 18^{\circ} \mathrm{C}$ sicaklikta ve $16 / 8 \quad 1$ şı periyodunda yapılmıştır. Denemeler birbirinden bağımsız en az 3 tekrar olacak şekilde yapılmıştır. Soğancık sayımı için, herbir deney kendi içinde en az 5 tekrar olacak şekilde tasarlanmıştır. Petri ortamında 4 adet eksplant, filtreli kültür kaplarında ise yaklaşık 6 eksplant kullanılmıştır. Yaklaşık 4 ay sonunda, soğancık oluşumu gözlenen eksplantlar sayılarak "soğancık görülme sıklığı" yüzde cinsinden hesaplanmıştır. Eksplantlar üzerinde oluşan soğancıklar sayılarak "Eksplant başına düşen soğancık sayısı" yüzde cinsinden ifade edilmiştir. Denemeler yaklaşık 4 hafta sonunda alt kültüre alınmıştır. Soğan pul yapraklarından elde edilen soğancıkların köklendirilmesi 1 $\mathrm{mg} \mathrm{l}^{-1}$ ve $5 \mathrm{mg}^{-1}$ aktif kömür içeren besiyerleri tüp ve filtreli kültür kapları kullanılarak yapılmıştır. Kök gelişimi tamamlanan soğancıklar, perlit içeren saksılarda dış ortama aktarılmıştır. Soğancıkların ekildiği saksıların üzerine şeffaf poşetler geçirilerek 10 gün boyunca doğrudan hava ile teması engellenerek dış ortama alıştırılması sağlanmıştır.

\section{Bulgular}

Doğal ortamından toplanmış olgun kardelen soğanları (Galanthus woronowii) ticari çamaşır suyu kullanılarak steril edilmiştir. Sterilizasyon işlemi sonrasında yaklaşı $\% 50$ oranında eksplant kaybı gözlenmiştir. Bu nedenle, deney çalışmasının başlangıcında oldukça fazla sayıda petri ve filtreli kültür kabı ile çalışmaya başlanmıştır. Kardelen soğan pullarının sterilizasyonunu takiben doku kültürü ortamında yaklaşık 4 ay süre sonunda yüksek oranda soğancık oluşumu kaydedilmiştir. Çalışmamızda elde edilen veriler, köklenme ortamına alınabilecek büyüklüğe gelen soğanlar sayılarak elde edilmiştir. Ayrıca, bitkisel hormon ve aktif kömür içermeyen MS ortamında da soğancık oluşumu gözlenmiş olmasına rağmen oluşan soğancıklar sayılabilecek büyüklüğe ulaşmadığ için yeterli veri kaydı yapılamamıştır.

\subsection{Bitkisel Hormon Kombinasyonlarının Soğancık Oluşumuna Etkisi}

Bitkisel hormon kombinasyonlarının tamamında, soğancık oluşumu farklı oranlarda gözlenmiştir. Herbir eksplant üzerinde birden fazla sayıda soğancık oluşumu gerçekleşmiştir. Oluşan soğancık sayısı uygulanan bitkisel hormon içeriğine göre farkl1lık göstermiştir. $1 \mathrm{mg} \mathrm{l}^{-1} \mathrm{BAP}$ ve $0.1 \mathrm{mg} \mathrm{l}^{-1}$ NAA içeren MS ortamında tüm eksplantlarda soğancık oluşumu (\% 100) tespit edilmiştir. Çizelge 1'de belirtilen tüm hormon 
kombinasyonları içerisinde eksplant başına düşen en yüksek soğancık sayısı 3.67 ile $1 \mathrm{mg} \mathrm{l}^{-1}$ BAP ve $0.1 \mathrm{mg} \mathrm{l}^{-1} \mathrm{NAA}$ içeren MS ortamında bulunmuştur. Sitokinin (BAP) ve oksin (NAA) konsantrasyonu arttıkça soğancık oluşumunda azalma kaydedilmiştir. $2 \mathrm{mg} \mathrm{l}^{-1}$ BAP ve $0.2 \mathrm{mg} \mathrm{l}^{-1}$ NAA içeren MS ortamındaki eksplantlarda \% 76 oranında soğancık oluşumu elde edilmiştir. En düşük soğancık görülme sıklığı ise \% 20 oranında $1 \mathrm{mg} \mathrm{l}^{-1} \mathrm{BAP}, 0.1 \mathrm{mg} \mathrm{l}^{-1}$ NAA ve $0.1 \mathrm{mg} \mathrm{l}^{-1} \mathrm{GA}_{3}$ içeren MS ortamında gözlenmiştir. NAA ve 2,4-D içeren MS ortamlarında ise konsantrasyon arttıkça eksplant başına düşen soğancık sayısında azalma kaydedilmiştir (Çizelge 1). Tüm ortamlardan elde edilen soğancıklar 1 ve $5 \mathrm{mg} \mathrm{l}^{-1}$ aktif kömür içeren MS ortamında köklendirilerek, soğancıkların dış ortama aktarımları yüksek oranda başarı ile tamamlanmıştır.

\subsection{Aktif Kömürün Soğancık Oluşumuna Etkisi}

MS besiyeri ortamına 1 ve $5 \mathrm{~g} \mathrm{l}^{-1}$ oranında aktif kömür eklenerek, kardelen soğan pullarından elde edilen tüm eksplantlarda soğancık oluşumu teşvik edilmiştir. $5 \mathrm{~g} \mathrm{l}^{-1}$ aktif kömür içeren MS ortamında eksplant başına düşen soğancık sayısı 5.95 adet ile en yüksek verimi göstermiştir (Çizelge 2) (Şekil 1). $1 \mathrm{mg} \mathrm{l}^{-1}$ aktif kömür içeren MS ortamında ise 2.95 adet eksplant başına soğancık oluşumu bulunmuştur. MS ortamında aktif kömür ilavesi ile elde edilen soğancıklar $1 \mathrm{mg} \mathrm{l}^{-}$ ${ }^{1}$ ve $5 \mathrm{mg} \mathrm{l}^{-1}$ aktif kömür içeren MS ortamlarında başarılı bir şekilde köklenmiştir (Şekil 2). Köklenen soğancıkların dış ortama aktarımı perlit içeren saksılarda yapılmıştır (Şekil 2).
Çizelge 1. Bitkisel hormon kombinasyonlarının kardelen soğancık oluşumuna etkisi.

Table 1. The Effect of plant hormone combination on the formation of snowdrop bulblet.

\begin{tabular}{cccccc}
\hline \multicolumn{2}{c}{$\begin{array}{c}\text { Bitkisel Hormonlar } \\
\left(\mathrm{mg} \mathrm{1}^{-1}\right)\end{array}$} & & $\begin{array}{c}\text { Soğancık } \\
\text { görülme } \\
\text { siklığı }(\%)\end{array}$ & $\begin{array}{c}\text { Eksplant başına } \\
\text { düşen soğancık } \\
\text { sayıs1 }\end{array}$ \\
\cline { 1 - 3 } BAP & NAA & $\mathrm{GA}_{3}$ & 2,4-D & & \\
\hline 1.00 & 0.1 & & & $100 \pm 0$ & $3.67 \pm 0.8$ \\
2.00 & 0.2 & & & $76.335 \pm 7.63$ & $3.07 \pm 0.6$ \\
1.00 & 0.1 & 0.1 & & $20 \pm 0$ & $1.13 \pm 0.1$ \\
& & 2.0 & & $35.56 \pm 3.8$ & $1.2 \pm 0.2$ \\
& 0.1 & & 1.00 & $45.71 \pm 5.08$ & $1.41 \pm 0.32$ \\
& 0.2 & & 2.00 & $37.89 \pm 4.77$ & $0.61 \pm 0.13$ \\
\hline
\end{tabular}

Çizelge 2. Aktif kömür içeren MS ortamında soğancık oluşumu.

Table 2. The bulblet formation in MS medium including activated charcoal.

\begin{tabular}{ccc}
\hline $\begin{array}{c}\text { Aktif Kömür } \\
\left(\mathrm{g} \mathrm{l}^{-1}\right)\end{array}$ & $\begin{array}{c}\text { Soğancık görülme } \\
\text { s1klığ }(\%)\end{array}$ & $\begin{array}{c}\text { Eksplant başına düşen } \\
\text { soğancık sayıs1 }\end{array}$ \\
\hline 1.0 & 100 & $2.552 \pm 0.27$ \\
5.0 & 100 & $5.95 \pm 0.78$ \\
\hline
\end{tabular}

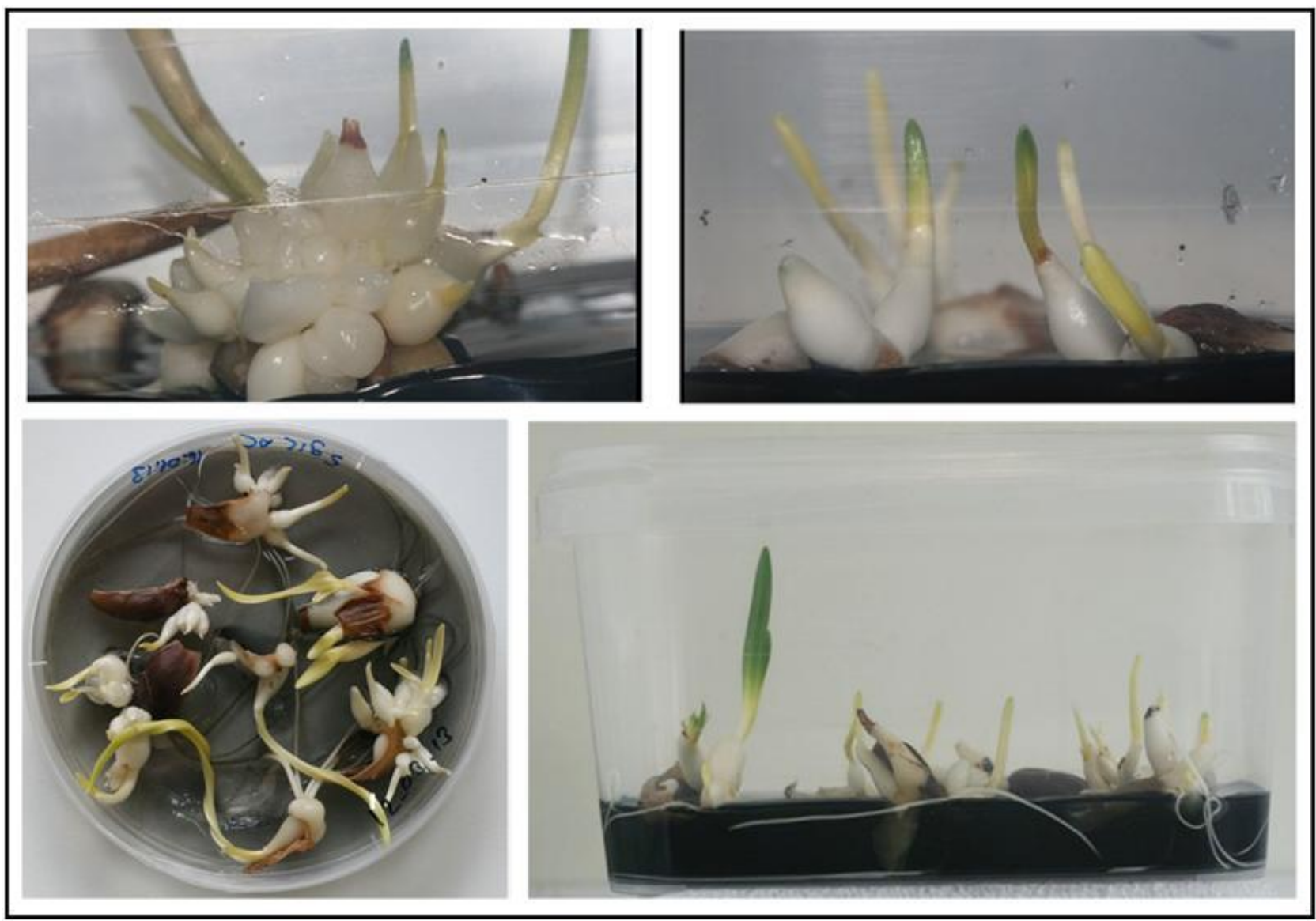

Şekil 1. $5 \mathrm{~g} \mathrm{l}^{-1}$ aktif kömür içeren MS besiyerinde soğancık oluşumu.

Figure 1. The bulblet formation in MS medium including $5 \mathrm{~g} \mathrm{I}^{-1}$ activated charcoal. 


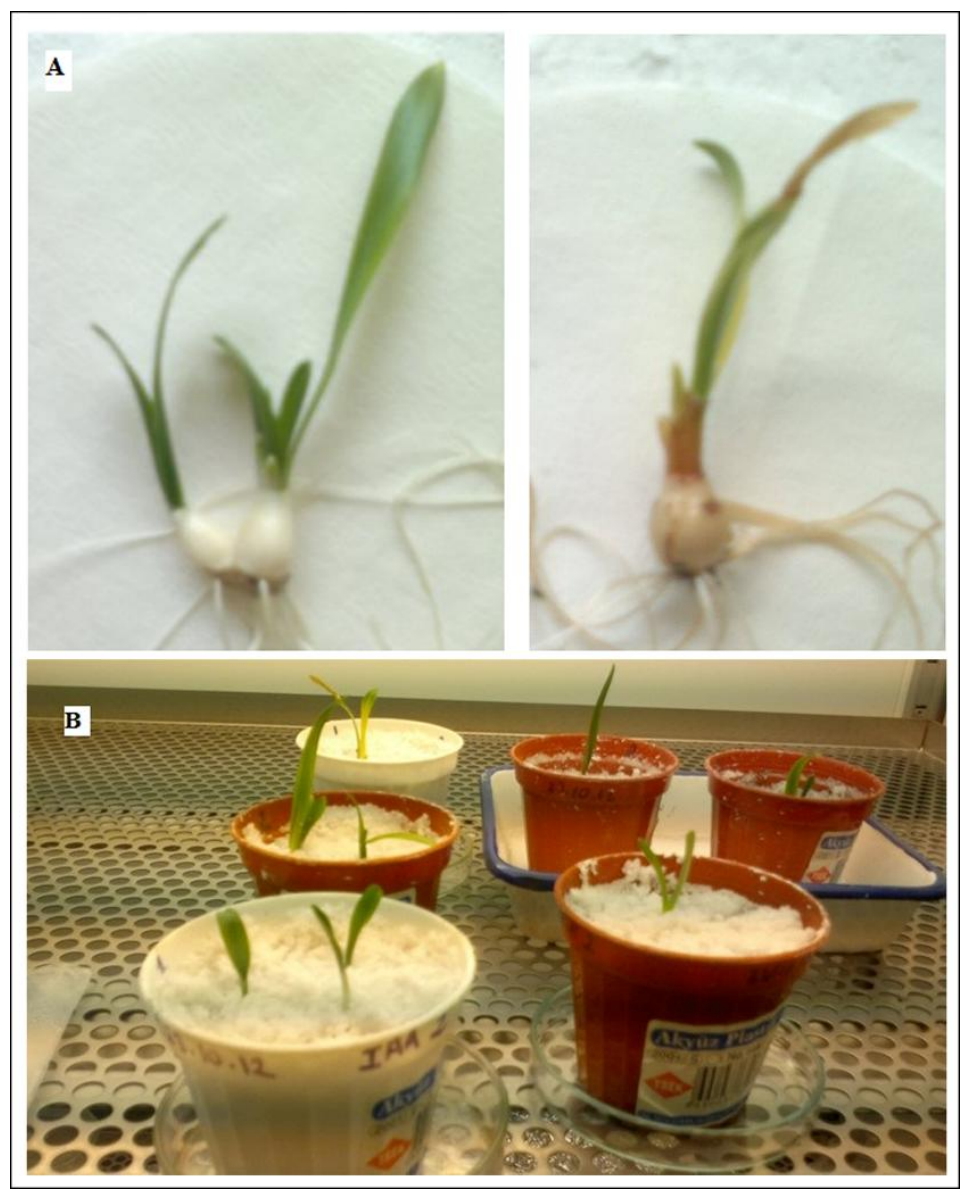

Şekil 2. $1 \mathrm{~g} \mathrm{l}^{-1}$ aktif kömür içeren MS besiyerin de köklendirilen kardelen soğancıkları (A). Doku kültürü koşullarında elde edilen soğancıkların dış ortama aktarilması (B).

Figure 2. Rooted snowdrop bulblets in MS medium including $1 \mathrm{gl}^{-1}$ activated charcoal (A). Acclimatization of bulblets obtaining from tissue culture condition (B).

\section{Tartışma ve Sonuç}

Bitkisel dokuların totipotensi özelliğinden yararlanarak geliştirilen bitki doku kültürü tekniği, günümüzde ticari ve bilimsel amaçlı birçok bitki türünün vegetatif üretiminde kullanılmaktadır. Vegetatif üretimi yapılacak olan bitkinin özelliğine göre, eksplant kaynağı farklı doku ve organlardan seçilmektedir. Geofit olarak bilinen soğanlı bitkilerin doku kültürü çalışmalarında, soğan ve rizom gibi toprak altı sürgünleri sıklıkla kullanılmıştır (Çı̆̆ ve Başdoğan 2015). Bu çalışmada, in vitro koşullarda, Karadeniz kardeleni (Galanthus woronowii) nin soğan pul yaprakları eksplant kaynağı olarak çalışılmıştır. Soğan pul yapraklarının tamamen steril edilmemesinden dolayı, eksplant kaybı yaşanmıştır. Ancak, olgun kardelen soğanından çok sayıda eksplant elde edilebildiği için, sürgün oluşumu sırasında problem yaşanmamıştır. Aktif kömür (Çizelge 2) ve $1 \mathrm{mg} \mathrm{l}^{-1}$ BAP ve $0.1 \mathrm{mg} \mathrm{l}^{-1}$ NAA içeren MS ortamlarında (Çizelge 1) tüm eksplantlarda soğancık oluşumu tespit edilmiştir. Kullanılan diğer MS ortamlarında da, soğan pul yapraklarında yüksek oranda soğancık oluşumu gözlenmiştir. Elde edilen veriler doğrultusunda, Karadeniz kardeleninin soğan pul yaprakları in vitro koşullarda, verimli bir eksplant kaynağı olarak kullanılabileceği sonucuna varılmıştır. Tıpırdamaz ve ark. (1999) da yaptıkları çalıșmada karadeniz kardeleninin soğan parçası, çift pul yaprak ve soğan pul yaprağı, bazal doku içermeyen pul yaprağının üst kısımlarını eksplant kaynağı olarak kullanmışlardır. En uygun eksplant kaynağının soğan pul yaprakları olduğunu ifade etmişlerdir.

Bitki doku kültürü çalışmalarında, bitki büyüme düzenleyicileri soğancık üretiminin teşvik edilmesinde oldukça önemli işlev görmektedir. Bitki büyüme düzenleyicilerinin oranları ve karışım halinde kullanımı soğancık verimini etkileyen önemli faktörler arasındadır. Bu çalışma ile, sitokinin kaynağı olarak BAP, oksin kaynağı olarak NAA kullanımının soğancık veriminde yüksek etkisi bulunmuştur. BAP ve NAA hormonlarının konsantrasyonu arttırıldığında, soğancık görülme sıklığı ve eksplant başına düşen soğancık sayısında azalma gözlenmiştir (Çizelge 1). Karadeniz kardelen soğanının in vitro koşullarda üretiminde, $1 \mathrm{mg} \mathrm{l}^{-1} \mathrm{BAP}$ ve $0.1 \mathrm{mg} \mathrm{l}^{-1}$ NAA bitkisel hormonları içeren MS ortamında en yüksek soğancık oluşumu bulunmuştur. Galanthus nivalis ile yapılan bir çalışmada, şoğan pullarından farklı oranlarda BAP ve NAA kullanarak in vitro koşullarda soğancık üretimi yapılmıştır (Staikidou ve Selby 2012) ve BAP ve NAA konsantrasyonu azaldıkça, soğancık veriminde azalma bulunmuş, $1 \mathrm{mg} \mathrm{l}^{-1} \mathrm{BAP}$ ve $0.1 \mathrm{mg} \mathrm{l}^{-1}$ NAA içeren ortamda en uygun soğancık oluşumu rapor edilmiştir.

Aktif kömür, bitki doku kültürü çalışmalarında hücre büyüme ve gelişmesinin teşvik edilmesinde sıklıkla kullanılmaktadır (Thomas 2008). Doku kültürü ortamına aktif kömür eklenmesi, fenolik oksidasyonu önemli miktarda azaltarak, en uygun morfogenez oluşumu için ortamın $\mathrm{pH}$ sını düzenlemektedir (Thomas 2008). Kardelen türleri ile yapılan 
çalışmalarda, aktif kömür uygulamasının, in vitro koşullarda soğancıkların büyümesi ve köklendirilmesini arttırdığ bulunmuştur (Staikidou ve ark. 2006; Staikidou ve Selby 2012). $\mathrm{Bu}$ çalı̧̧mada ise, kardelen soğan pullarından alınan eksplantlar da, $5 \mathrm{mg} \mathrm{l}^{-1}$ aktif kömür içeren MS ortamında yaklaşı 6 adet soğancık oluşumu gözlenmiştir ve uygulanan tüm ortamlar içerisinde en yüksek verim elde edilmiştir. Doku kültürü yöntemi ile kardelen soğancık üretiminde, aktif kömür kullanımının etkili ve verimli sonuç verdiği bulunmuştur.

Sonuç olarak, doku kültürü yöntemi ile kardelen soğanının üretimi başarılı bir şekilde tamamlanmış ve soğancıkların dış ortama aktarımı gerçekleşmiştir. Çalışmamızda, in vitro koşullarda aktif kömürün Karadeniz kardelen soğan pullarından yüksek sayıda soğancık oluşumunu teşvik ettiği ortaya konmuştur.

\section{Teşekkür}

$\mathrm{Bu}$ çalışma Bilim, Sanayi Teknoloji Bakanlığı 1457.TGSD.2012 nolu ve İstanbul Üniversitesi Bilimsel Araştrıma Projeleri Koordinasyon Birimi 41364 nolu projeler tarafindan desteklenmiştir.

\section{Kaynaklar}

Anonim (2004) Doğal çiçek Soğanlarının sökümü, üretimi ve ticaretine ilişkin yönetmelik. Resmi Gazete 24 Ağustos 2004, Ankara.

Çakırlar H, Tıpırdamaz R, Ellialtıoğlu Ş (1994) Türkiye'de ticari değeri olan Galanthus (G. Elwesii Hooker Fil. Ve G. ikariae Baker.) türlerinin doku kültürü yoluyla üretimi. TÜBİTAK projesi TBGAG-19/A.

Çı̆̆ A, Başdoğan G (2015) In vitro propagation techniques for some geophyte ornamental plants with high economic value. International Journal of Secondary Metabolite 2(1): 27-49.

Daneshvar-Royandazagh S, Pehlivan EC, Teykin EE, Çiftçi HS (2014) Lilium candidum L.'da In vitro mikroçoğaltım ile kozmetik sanayisine ham madde temini. Turkish Journal of Agricultural and Natural Sciences 2: 1911-1916.

Demir A (2010) Türkiye'de kardelen ticareti ve politik yaklaşımlar. Biological Diversity and Conservation 3(3): 111-120.

Ekim T, Arslan N, Koyuncu M (1992) Exported flower bulbs from Turkey and measurements taken. Acta Horticulturae 325: 861-865.

Murashige T, Skoog F (1962) A revised medium for rapid growth and bioassays with tobacco tissue cultures. Plant Physiology 15: 473497.

Nasırcılar AG, Karagüzel Ö (2006) Galanthus elwesii Hook. bitkisinin olgunlaşmamış embriyolarından in vitro soğan üretimi. Akdeniz Üniversitesi Ziraat Fakültesi Dergisi 19(2): 159-164.

Özdemir FA, Yildirim MU, Kahriz MP, Kiliç Ö (2016) In vitro bulblet regeneration from Scilla Siberica Haw. subsp. armena (Grossh.) mordak peduncle. Propagation of Ornamental Plants 16(1): 14-18.

Staikidou I, Selby C, Hanks G (2006) Stimulation of in vitro bulblet growth in Galanthus species with sucrose and activated charcoal. Acta Horticulturae 725: 421-426.

Staikidou I, Selby C (2012) Effects of growth regulators and activated charcoal on in vitro bulblet multification and growth in Galanthus nivalis "Flore Pleno". The Journal of Horticultural Science and Biotechnology 87: 527-530.

Thomas D (2008) The role of activated charcoal in plant tissue culture. Biotechnology Advances 26: 618-631.

Tıpırdamaz R, Ellialtıoğlu S, Çakirlar H (1999) The micropropagation of snowdrop (Galanthus ikariae Baker): effects explant type, carbonhydrate source and dose and $\mathrm{pH}$ changes in the medium on bulblet formation. Turkish Journal of Agriculture \& Forestry 23(4): 823-830.
Tipırdamaz R (2003) Rooting and acclimatization of in vitro micropropagated snowdrop (Galanthus ikariae Baker) bulblets. Akdeniz Üniversitesi Ziraat Fakültesi Dergisi 16: 121-126.

Ulus A, Seyidoğlu N (2006) Bazı doğal geofitlerin doku kültürü ile üretimi. İstanbul Üniversitesi Orman Fakültesi Dergisi 56:1 71-80.

Yüzbaşığlu S (2008) The development of non-detriment findings for Galanthus elwesii Hook. f., in Turkey. NDF Workshop Case Studies, Mexico, pp. 1-13.

Yüzbaşığlu S (2012) Morphological variations of Galanthus elwesii in Turkey and difficulties on identification. Bocconea 24: 335-339. 